(c) American Dairy Science Association, 2006.

\title{
Computer-Controlled Milk Feeding of Group-Housed Calves: The Effect of Milk Allowance and Weaning Type
}

\author{
M. B. Jensen \\ Department of Animal Health, Welfare and Nutrition, Danish Institute of Agricultural Sciences, \\ Research Centre Foulum, 8830 Tjele, Denmark
}

\begin{abstract}
Calves fed by computer-controlled milk feeders are often weaned gradually by reducing the size of the milk portions. However, reducing the number of milk portions instead may lower calves' occupation of the milk feeder and stimulate their concentrate intake, especially when they are offered a high milk allowance. Before weaning, but not during weaning, the calves on low milk allowance occupied the milk feeder more, consumed more concentrates, and had a lower daily gain. There was no interaction between milk allowance and weaning type. Weaning by reducing the number of milk portions resulted in more unrewarded visits to the milk feeder, but less time ingesting a similar amount of milk. The effect of milk allowance on milk feeder occupancy before weaning was not found when this allowance was halved during weaning.
\end{abstract}

Key words: calf, milk-feeding, feeding behavior, weaning

\section{INTRODUCTION}

When a computer-controlled milk feeder is used, it is convenient to wean the calves off milk gradually over a couple of weeks. This is typically done by first reducing the size of the milk portions and then reducing the number of milk portions. However, offering a daily milk allowance of $6 \mathrm{~L} / \mathrm{d}$ in 4 rather than 8 daily portions lowered milk feeder occupancy (Jensen, 2004). Similarly, during gradual weaning, feeding fewer milk portions may reduce the milk feeder occupancy and stimulate the intake of solid foods. The transition from milk to solid food may cause a lag in growth, especially when the milk allowance is high (Hepola, 2003). The aim of the present study was to investigate the interactive effects of milk allowance and type of gradual weaning on calves' use of a computer-controlled milk feeder, and on concentrate intake and daily gain.

Received May 26, 2005.

Accepted August 30, 2005.

E-mail: MargitBak.Jensen@agrsci.dk

\section{MATERIALS AND METHODS}

Ninety-six male and female calves (27 HolsteinFriesians, 42 Danish Reds, and 27 Jersey calves) were housed and fed as described by Jensen (2004) from birth until being moved to the experimental pens at $\mathrm{d} 12$. Each of the experimental pens measured $9.30 \times 4.35$ $\mathrm{m}$, and were bedded with straw and equipped with 2 milk feeders and 2 concentrate feeders served by one computer-controlled feeder unit (HL100; Calvex, Højslev, Denmark). Sixteen calves were allocated to each of 6 blocks, and the calves of each block were housed in 1 experimental pen. The age range within block was $23 \pm 4 \mathrm{~d}$. The calves were fed milk replacer (Friska Sød, Dansk Landbrugs Grovvareselskab, Denmark) based on defatted milk powder (60\%), whey powder (18\%), and vegetable fat (18\%), and containing $24 \%$ $\mathrm{CP}$ and $19 \%$ fat (145 g of milk replacer/L of water). The calves were offered either a high allowance $(8.0 \mathrm{~L} / \mathrm{d}$ for the heavy breeds and $6.4 \mathrm{~L} / \mathrm{d}$ for Jersey), or a low allowance $(4.8 \mathrm{~L} / \mathrm{d}$ for the heavy breeds and $3.8 \mathrm{~L} / \mathrm{d}$ for Jersey) in 4 daily portions. The low milk allowance of the heavy breeds corresponded to the Danish recommendations (Anonymous, 2004), and the low milk allowance of the Jersey calves was $80 \%$ of that value. The recommended allowance for Jersey calves is $60 \%$ of the recommended allowance for calves of the heavy breeds. However, when Jersey calves were offered $60 \%$ of the allowances used for the heavy breeds in a previous experiment, no effect of milk allowance was found among the Jersey calves (Jensen and Holm, 2003). Therefore, the Jersey calves were offered $80 \%$ of the allowances of the heavy breeds. The calves were allocated to treatment at $8 \mathrm{~d}$ of age and for calves that were offered a high milk allowance, the allowance was gradually increased from $\mathrm{d} 8$ to 16 . All calves were weaned gradually from d 52 to 68 . Half of the calves on each milk allowance were weaned by reducing the portion size (while maintaining the number of portions constant), whereas the other half was weaned by reducing the number of milk portions (while maintaining the portion size constant). The milk allowance and number of milk portions for calves of the heavy breeds are shown in Table 1. 
Table 1. The daily milk allowance (high or low) and minimum number of daily milk portions (L/no. of portions) for calves of the large breeds

\begin{tabular}{|c|c|c|c|c|}
\hline \multirow[b]{3}{*}{ Age, $d$} & \multicolumn{4}{|c|}{ Weaning method and milk allowance } \\
\hline & \multicolumn{2}{|c|}{$\begin{array}{l}\text { Reduce size } \\
\text { of portions }\end{array}$} & \multicolumn{2}{|c|}{$\begin{array}{l}\text { Reduce number } \\
\text { of portions }\end{array}$} \\
\hline & High & Low & High & Low \\
\hline $16-51$ & $8.0 / 4$ & $4.8 / 4$ & $8.0 / 4$ & $4.8 / 4$ \\
\hline 52 & $7.6 / 4$ & $4.6 / 4$ & $8.0 / 4$ & $4.8 / 4$ \\
\hline 53 & $7.2 / 4$ & $4.4 / 4$ & $8.0 / 4$ & $4.8 / 4$ \\
\hline 54 & $6.8 / 4$ & $4.2 / 4$ & $6.0 / 3$ & $4.8 / 4$ \\
\hline 55 & $6.4 / 4$ & $4.0 / 4$ & $6.0 / 3$ & $3.6 / 3$ \\
\hline 56 & $6.0 / 4$ & $3.8 / 4$ & $6.0 / 3$ & $3.6 / 3$ \\
\hline 57 & $5.6 / 4$ & $3.6 / 4$ & $6.0 / 3$ & $3.6 / 3$ \\
\hline 58 & $5.2 / 4$ & $3.4 / 4$ & $6.0 / 3$ & $3.6 / 3$ \\
\hline 59 & $4.8 / 4$ & $3.2 / 4$ & $6.0 / 3$ & $3.6 / 3$ \\
\hline 60 & $4.4 / 4$ & $3.0 / 4$ & $4.0 / 2$ & $3.6 / 3$ \\
\hline 61 & $4.0 / 4$ & $2.8 / 4$ & $4.0 / 2$ & $2.4 / 2$ \\
\hline 62 & $3.6 / 4$ & $2.6 / 4$ & $4.0 / 2$ & $2.4 / 2$ \\
\hline 63 & $3.2 / 4$ & $2.4 / 4$ & $2.0 / 2$ & $2.4 / 2$ \\
\hline 64 & $2.8 / 4$ & $2.2 / 4$ & $2.0 / 1$ & $2.4 / 2$ \\
\hline 65 & $2.4 / 4$ & $2.0 / 4$ & $2.0 / 1$ & $1.2 / 1$ \\
\hline 66 & $2.0 / 4$ & $1.8 / 4$ & $2.0 / 1$ & $1.2 / 1$ \\
\hline 67 & $2.0 / 4$ & $1.6 / 4$ & $2.0 / 1$ & $1.2 / 1$ \\
\hline 68 & 0 & 0 & 0 & 0 \\
\hline
\end{tabular}

Among the 16 calves allocated to each block, 4 were allocated to each of the 4 treatments: 1 ) high milk and weaning by reduced portion size, 2) low milk and weaning by reduced portion size, 3) high milk and weaning by reduced number of portions, or 4) low milk and weaning by reduced number of portions. Concentrates [Grøn Kalv Valset; Dansk Landbrugs Grovvareselskab, Denmark (18\% CP, $4 \%$ fat, and 6\% fiber)] and hay were available ad libitum throughout the experiment. The computer-controlled feeder unit recorded and stored data regarding the calves' use of the milk feeder and milk intake as described by Jensen (2004), as well as the visits to the concentrate feeder and concentrate intake. Before weaning (d 22 to 49), an average across days within each of the $4 \mathrm{wk}$ was calculated for each calf, and used as input data in the statistical analyses. During weaning, data were collected during the days where the milk allowance was approximately half of what it was before weaning for all 4 treatments (d 61 to 63). After weaning (d 71 to 77), only the use of the concentrate feeder and the concentrate intake were recorded. The calves were weighed at birth, at d 12, and thereafter every $14 \mathrm{~d}$ until $\mathrm{d} 82$. The daily gain in each of the 5 periods was calculated and analyzed. Three diseased calves were removed before weaning, 8 calves were excluded during weaning, and 5 calves were excluded after weaning due to wrong milk feeder programming. All variables were analyzed using mixed models including the random effect of block. Before weaning, the model included the fixed effect of milk allowance, breed, sex, milk allowance $\times$ breed, period, and milk allowance $\times$ period. During and after weaning, the model included the fixed effect of weaning type, milk allowance, weaning type $\times$ milk allowance, breed, sex, and milk allowance $\times$ breed.

\section{RESULTS AND DISCUSSION}

Before weaning, the calves on a low milk allowance had higher milk feeder occupancy due to having more than twice the number and duration of unrewarded visits to the feeder compared with the calves on high milk allowance (Table 2). Similar effects of milk allowance were reported by Hammon et al. (2002) and Jensen and Holm (2003), and the many unrewarded visits most likely reflect hunger. For comparison, calves fed ad libitum consumed up to $10 \mathrm{~L} / \mathrm{d}$ at weaning (Jasper and Weary, 2002). The unrewarded occupancy decreased over the weeks before weaning for the low-fed calves (Table 3), which may reflect that the fact that lowfed calves focused less on the milk and more on the concentrate as they grew older.

The low-fed calves spent less time ingesting the milk, but they spent more time in the feeder after milk ingestion (Table 2). This most likely reflects non-nutritive sucking in connection with milk intake, because the sucking motivation is stimulated by ingestion of milk and declines within 10 min (de Passillé et al., 1992). When calves spend little time performing nutritive sucking, they may perform more non-nutritive sucking afterwards. However, more non-nutritive sucking may be related to hunger because reducing the milk allowance by $25 \%$ increased non-nutritive sucking of a teat after the milk meal (Rushen and de Passillé, 1995).

The high-fed calves averaged 1 more milk meal per $24 \mathrm{~h}$ than did low-fed calves (Table 2), although the computer was set up to allow calves on both milk allowances their ration in a minimum of 4 portions. Short interruptions of rewarded visits may account for the number of rewarded visits being greater than 4 . The higher number of rewarded visits in the high-fed calves could suggest that the predetermined maximum portion size was above a preferred meal size, but this needs further investigation. Female calves had more meals per $24 \mathrm{~h}$ than male calves $\left(5.4 \pm 0.2\right.$ vs. $4.8 \pm 0.2 ; \mathrm{F}_{1}$, $93=7.02 ; P=0.01$ ), and this may either be because the females were more interrupted by other calves during rewarded visits or because the preferred meal size is affected by sex.

The Jersey calves spent more time in the milk feeder due to more time on unrewarded visits compared with calves of the heavy breeds (Table 4). Jersey calves are smaller than calves of the other 2 breeds, and Jensen (2004) found that Jersey calves were more frequently displaced than were calves of the heavy breeds. The 
Table 2. Main effects of milk allowance before, during, and after weaning

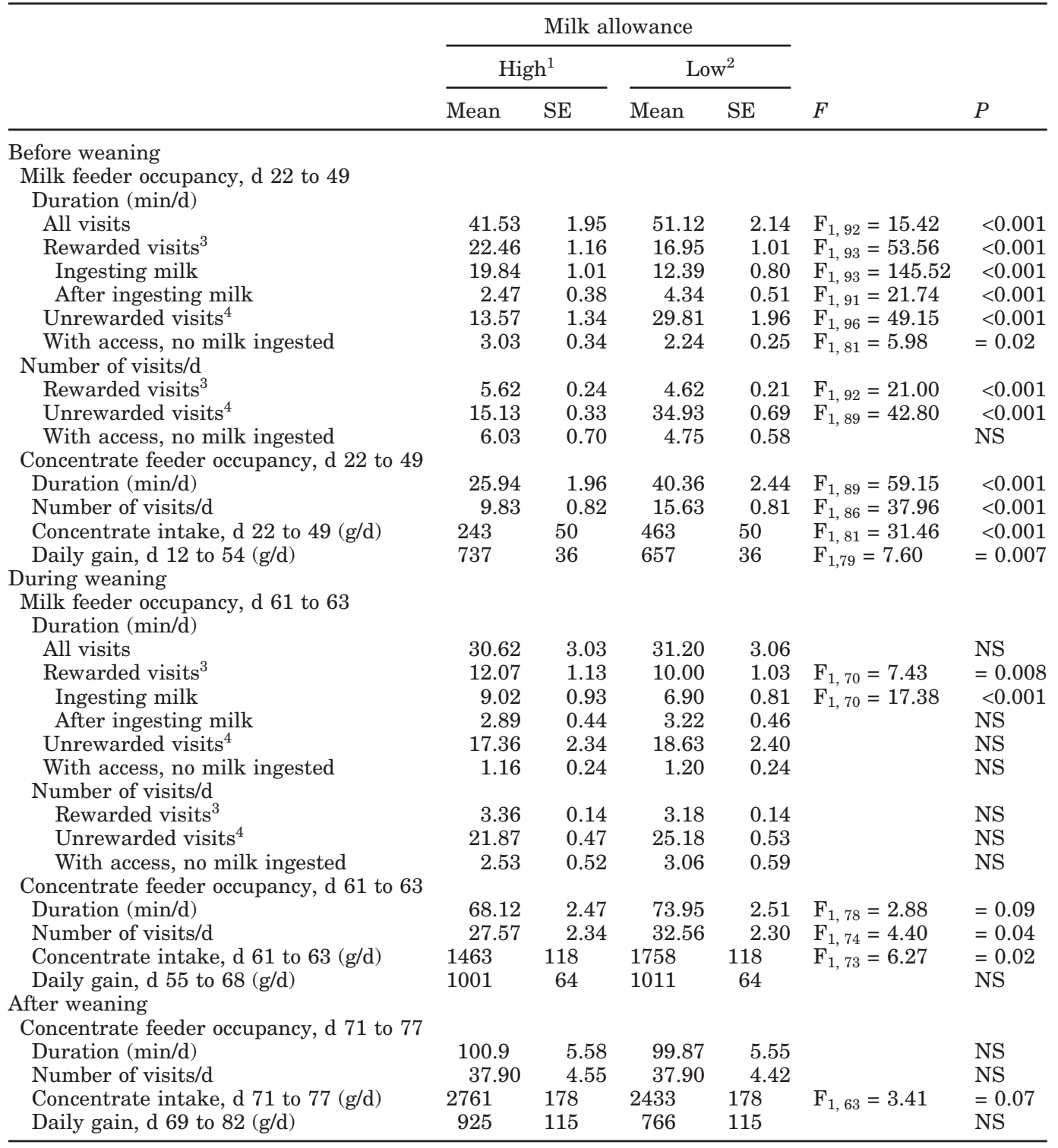

${ }^{1}$ High milk allowance: $8.0 \mathrm{~L} / \mathrm{d}$ for heavy breeds and $6.4 \mathrm{~L} / \mathrm{d}$ for Jersey.

${ }^{2}$ Low milk allowance: $4.8 \mathrm{~L} / \mathrm{d}$ for heavy breeds and $3.8 \mathrm{~L} / \mathrm{d}$ for Jersey.

${ }^{3}$ Visits where the calf had milk in the feeder, including time spent ingesting milk and time spent in the feeder just after ingesting milk.

${ }^{4}$ Visits where the calf did not have access to milk in the feeder.

more unrewarded visits may relate to the Jersey calves having more difficulty in getting access to the feeder at appropriate intervals.

During weaning, there were no interactions between milk allowance and weaning type for any of the variables. Weaning type had no effect on the total milk feeder occupancy. Weaning by reducing the number of milk portions resulted in less time spent ingesting milk (Table 5), which may be because it takes longer to fill and empty the tubes when a given amount is divided into more portions. The calves weaned by reducing the number of milk portions tended to spend less time in the milk feeder immediately after ingesting milk. A significant effect was expected here, because the weaning type was associated with a difference in the number of daily milk portions at a given milk allowance. A higher number of milk portions was found to increase the time in the milk feeder immediately after ingesting milk and total milk feeder occupation before the initiation of gradual weaning (Jensen, 2004). The calves 
Table 3. Main effect of week and week $\times$ milk allowance interactions before weaning ${ }^{1}$

\begin{tabular}{|c|c|c|c|c|c|c|c|c|c|c|}
\hline \multirow[b]{2}{*}{ Milk feeder occupancy } & \multicolumn{8}{|c|}{ Week } & \multirow[b]{2}{*}{$\mathrm{F}$} & \multirow[b]{2}{*}{$P$} \\
\hline & Mean & $\mathrm{SE}$ & Mean & $\mathrm{SE}$ & Mean & $\mathrm{SE}$ & Mean & $\mathrm{SE}$ & & \\
\hline \multicolumn{11}{|l|}{ Duration (min/d) } \\
\hline \multicolumn{11}{|l|}{ All visits } \\
\hline High milk & 44.96 & 2.37 & 42.99 & 2.32 & 40.38 & 2.25 & 37.95 & 2.18 & \multirow[t]{2}{*}{$\mathrm{F}_{3,263}=3.72$} & \multirow[t]{2}{*}{$=0.01$} \\
\hline Low milk & 62.00 & 2.74 & 54.28 & 2.57 & 47.03 & 2.39 & 42.27 & 2.27 & & \\
\hline \multicolumn{11}{|l|}{ Unrewarded visits ${ }^{3}$} \\
\hline High milk & 12.48 & 1.58 & 14.31 & 1.69 & 14.71 & 1.71 & 12.84 & 1.60 & \multirow[t]{2}{*}{$\mathrm{F}_{3,259}=6.69$} & \multirow[t]{2}{*}{$<0.00$} \\
\hline Low milk & 38.64 & 2.73 & 31.89 & 2.48 & 27.47 & 2.30 & 22.42 & 2.08 & & \\
\hline \multicolumn{11}{|l|}{ Milk intake (L/d) } \\
\hline High milk & 6.47 & 0.10 & 6.91 & 0.07 & 6.79 & 0.10 & 7.00 & 0.07 & \multirow[t]{2}{*}{$\mathrm{F}_{3,91}=6.66$} & \multirow[t]{2}{*}{$<0.00$} \\
\hline Low milk & 4.32 & 0.10 & 4.29 & 0.07 & 4.23 & 0.10 & 4.33 & 0.07 & & \\
\hline \multicolumn{11}{|l|}{ Concentrate intake $(\mathrm{g} / \mathrm{d})$} \\
\hline
\end{tabular}

${ }^{1}$ Only significant effects are listed.

${ }^{2}$ Visits where the calf had milk in the feeder, including time spent ingesting milk and time spent in the feeder just after ingesting milk.

${ }^{3}$ Visits where the calf did not have access to milk in the feeder.

Table 4. Main effect of breed and breed $\times$ milk allowance interactions before, during, and after weaning ${ }^{1}$

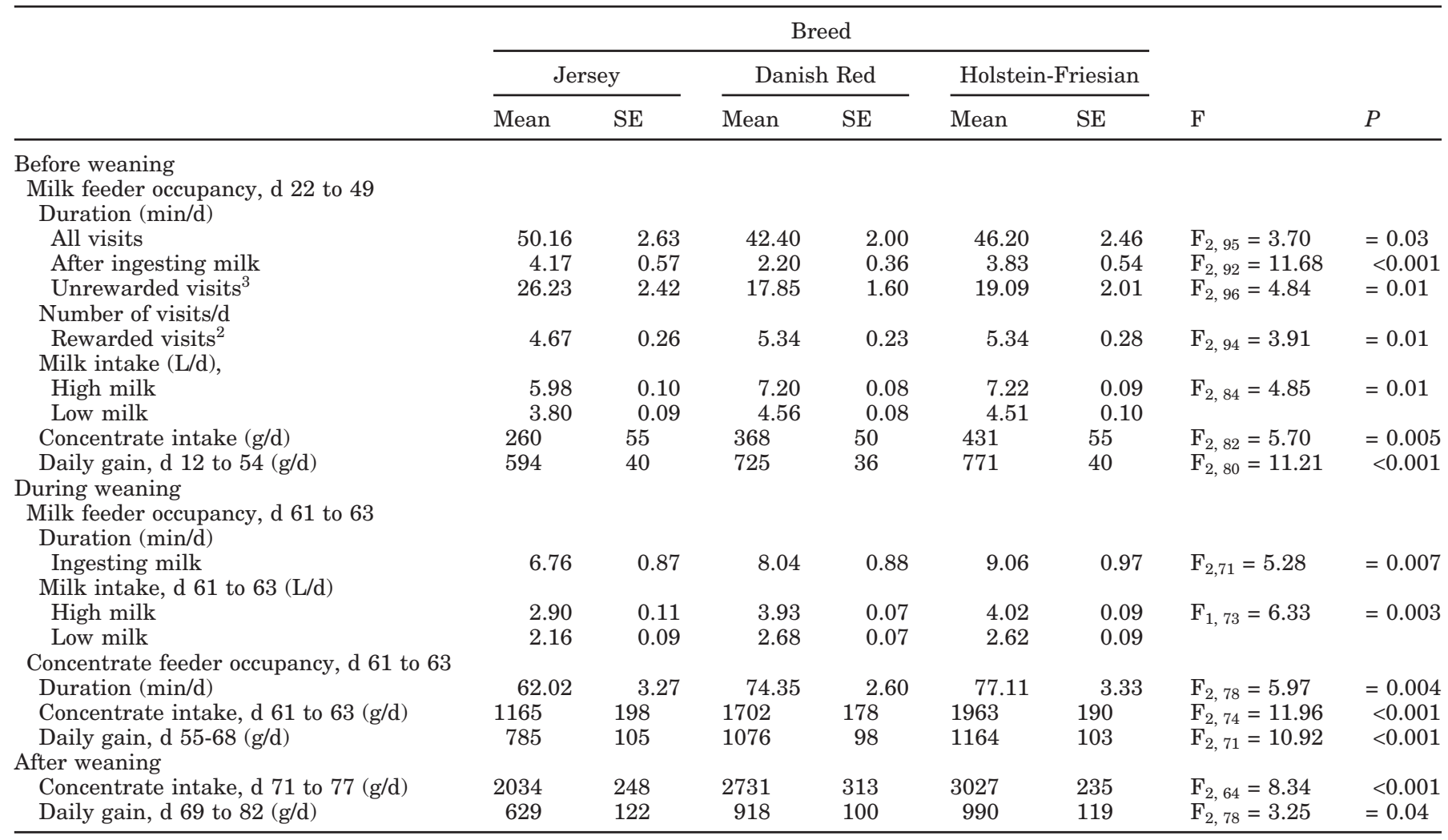

${ }^{1}$ Only significant effects are listed.

${ }^{2}$ Visits where the calf had milk in the feeder, including time spent ingesting milk and time spent in the feeder just after ingesting milk.

${ }^{3}$ Visits where the calf did not have access to milk in the feeder. 
Table 5. Main effect of weaning type during weaning

\begin{tabular}{|c|c|c|c|c|c|c|}
\hline & \multicolumn{4}{|c|}{ Type of weaning } & \multirow[b]{3}{*}{$F$} & \multirow[b]{3}{*}{$P$} \\
\hline & \multicolumn{2}{|c|}{ Reduce portion size ${ }^{1}$} & \multicolumn{2}{|c|}{ Reduce portion number ${ }^{2}$} & & \\
\hline & Mean & $\mathrm{SE}$ & Mean & SE & & \\
\hline \multicolumn{7}{|l|}{ Milk feeder occupancy, d 61 to 63} \\
\hline \multicolumn{7}{|l|}{ Duration (min/d) } \\
\hline All visits & 30.36 & 3.02 & 31.48 & 3.07 & & NS \\
\hline Rewarded visits ${ }^{3}$ & 11.77 & 1.12 & 10.28 & 1.04 & $\mathrm{~F}_{170}=3.90$ & $=0.06$ \\
\hline Unrewarded visits ${ }^{4}$ & 15.65 & 2.20 & 20.48 & 2.55 & $\mathrm{~F}_{174}=5.42$ & $=0.03$ \\
\hline With access, no milk & 1.42 & 0.29 & 0.98 & 0.21 & & NS \\
\hline \multicolumn{7}{|l|}{ Number of visits/d } \\
\hline Rewarded visits ${ }^{3}$ & 4.09 & 0.16 & 2.45 & 0.13 & $\mathrm{~F}_{1,75}=89.56$ & $<0.001$ \\
\hline Unrewarded visits ${ }^{4}$ & 19.39 & 0.42 & 27.98 & 0.58 & $\mathrm{~F}_{173}=10.45$ & $=0.002$ \\
\hline With access, no milk ingested & 3.30 & 0.63 & 2.30 & 0.48 & & NS \\
\hline Milk intake, d 61 to $63(\mathrm{~L} / \mathrm{d})$ & 3.06 & 0.05 & 3.05 & 0.05 & & NS \\
\hline
\end{tabular}

${ }^{1}$ Reduce portion size: calves weaned by reducing the portion size, while maintaining the number of portions constant.

${ }^{2}$ Reduce portion number: calves weaned by reducing the number of milk portions, while maintaining the portion size constant.

${ }^{3}$ Visits where the calf had milk in the feeder, including time spent ingesting milk and time spent in the feeder just after ingesting milk.

${ }^{4}$ Visits where the calf did not have access to milk in the feeder.

weaned by reducing the number of milk portions had more unrewarded visits and spent more time in unrewarded occupancy (Table 5), which may be because these calves were still expecting 4 daily portions. However, it is worth noting that during weaning, approximately $60 \%$ of milk feeder occupancy was unrewarded irrespective of milk allowances. This suggests that both high- and low-fed calves reacted to the gradual weaning by visiting the feeder frequently in an attempt to get more milk.

Before weaning, the low-fed calves visited the concentrate feeder more frequently, occupied it more, and consumed more concentrates, but had a lower daily gain (Table 2) than the high-fed calves. A lower daily gain was also found in Holstein-Friesian calves offered 4.1 compared with $6.7 \mathrm{~kg}$ of whole milk/d from birth to 7 wk, in which average daily gains of 538 and $615 \mathrm{~g} / \mathrm{d}$, respectively, were reported (Huber et al., 1984). Thus, the increased intake of concentrates could not compensate for the lower milk intake. Moreover, during weaning the concentrate intake was higher for the low-fed calves (Table 2), but after weaning no difference was found. There was no effect of milk allowance on daily gain during and after weaning in this study. The daily gain increased over the milk feeding period (517, 717, and $855( \pm 37) \mathrm{g} / \mathrm{d}$ for d 12 to $26, \mathrm{~d} 27$ to 40 , and d 41 to 54 , respectively; $\mathrm{F}_{2,178}=59.11 ; P<0.001$ ). The Jersey calves had a lower daily gain than the 2 other breeds before, during, and after weaning (Table 4).

In conclusion, the milk allowance affected milk feeder occupancy, concentrate intake, and daily gain before the initiation of gradual weaning. When the milk allowance was halved during gradual weaning there was no effect of milk allowance, but for all calves, approximately $60 \%$ of milk feeder occupancy was unrewarded. Weaning by reducing the number of milk portions resulted in more unrewarded visits to the milk feeder, but less time ingesting the milk, irrespective of milk allowance. Based on the present results, it is recommended to offer a high milk allowance to calves fed by a computer-controlled milk feeder, because the calves should be more satiated, and the total milk feeder occupancy would be lower. However, when calves are gradually weaned over a couple of weeks, as in the present experiment, the type of gradual weaning appears to have little effect.

\section{ACKNOWLEDGMENTS}

The Danish Livestock Federation and The Danish Ministry of Food, Agriculture and Fisheries supported this study. Thanks to Kathrine Larsen, Jane Eriksen, Erik L. Decker, and John Misa Obidah for assistance and to Mette Svendsen Herskin and Lene Juul Pedersen for comments on an early version of the manuscript.

\section{REFERENCES}

Anonymous. 2004. Handbook on Cattle Production—2004 (Håndbog i Kvæghold-2004). Landbrugsforlaget, Århus, Denmark. de Passillé, A. M., J. H. M. Metz, P. Mekking, and P. R. Wiepkema. 1992. Does drinking milk stimulate sucking in young calves? Appl. Anim. Behav. Sci. 34:23-36. 
Hammon, H. M., G. Schiessler, A. Nussbaum, and J. W. Blum. 2002. Feed intake patterns, growth performance, and metabolic and endocrine traits in calves fed unlimited amounts of colostrum and milk by automate, starting in the neonatal period. J. Dairy Sci. 85:3352-3362.

Hepola, H. 2003. Milk feeding systems for dairy calves in groups: Effects of feed intake, growth and health. Appl. Anim. Behav. Sci. 80:233-243.

Huber, J. T., A. G. Silva, O. F. Campos, and C. M. Mathieu. 1984. Influence of feeding different amounts of milk on performance, health, and absorption capacity of baby calves. J. Dairy Sci. 67:2957-2963.
Jasper, J., and D. M. Weary. 2002. Effects of ad libitum milk intake on dairy calves. J. Dairy Sci. 85:3054-3058.

Jensen, M. B. 2004. Computer-controlled milk feeding of dairy calves: The effects of number of calves per feeder and number of milk portions on use of feeder and social behavior. J. Dairy Sci. 87:3428-3438.

Jensen, M. B., and L. Holm. 2003. The effect of milk flow rate and milk allowance on feeding related behaviour in dairy calves fed by computer-controlled milk feeders. Appl. Anim. Behav. Sci. 82:87-100.

Rushen, J., and A. M. de Passillé. 1995. The motivation of non-nutritive sucking in calves, Bos taurus. Anim. Behav. 49:1503-1510. 